See Article page 1408.

\section{Commentary: Antlers, Christmas trees, and pulmonary veins}

\author{
Christopher A. Caldarone, MD
}

In this issue of the Journal, Shi and colleagues ${ }^{1}$ report a single-center series examining the impact of sutureless repairs as a prophylactic strategy to prevent postrepair pulmonary vein stenosis in a high risk subset of patients with total anomalous pulmonary venous connection. Specifically, patients with infracardiac drainage are often challenging to repair because of the variability in the morphology of the pulmonary vein confluence. Consequently, the use of conventional techniques with a direct anastomosis between the left atrium and the pulmonary veins requires considerable skill to construct the anastomosis without any geometric distortion of the pulmonary veins. Because the pulmonary veins are part of a low-pressure system, any error in the relationship between the atrial incision and the divided pulmonary venous confluence or any purse-stringing of the suture line can create the nidus for postrepair pulmonary vein stenosis. Despite the limitations of relatively short follow-up and potential for era bias, Dr Shi's group adds to a number of studies suggesting that sutureless repairs are safe and effective in diminishing the risk or postrepair pulmonary vein stenosis in high risk subsets.

The novelty of the current article by Shi and colleagues, ${ }^{1}$ however, is based on the observation that infracardiac total anomalous pulmonary venous connection can be subclassified into 2 types: the "inverted Christmas tree" and the "antler configuration" (the newly described antler configuration is clearly described and nicely illustrated in Figure 1 of the article). Shi and colleagues ${ }^{1}$ note that the antler

From the Division of Congenital Heart Surgery, Departments of Surgery and Pediatrics, Baylor College of Medicine and Texas Childrens Hospital, Houston, Tex.

Disclosures: The author reported no conflicts of interest.

The Journal policy requires editors and reviewers to disclose conflicts of interest and to decline handling or reviewing manuscripts for which they may have a conflict of interest. The editors and reviewers of this article have no conflicts of interest.

Received for publication July 12, 2020; revisions received July 12, 2020; accepted for publication July 13, 2020; available ahead of print July 16, 2020.

Address for reprints: Christopher A. Caldarone, MD, Division of Congenital Heart Surgery, Departments of Surgery and Pediatrics, Baylor College of Medicine, Texas Children's Hospital, 6651 Main St, Mail code 19345H, Houston, TX 77030 (E-mail: cacaldar@texaschildrens.org).

J Thorac Cardiovasc Surg 2021;161:1418

0022-5223/\$36.00

Copyright $₫ 2020$ Published by Elsevier Inc. on behalf of The American Association for Thoracic Surgery

https://doi.org/10.1016/j.jtcvs.2020.07.041

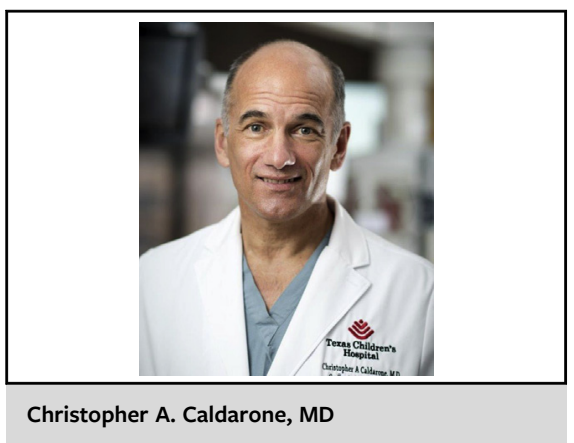

CENTRAL MESSAGE

In the face of complex geometry

(eg, antler configuration in total

anomalous pulmonary venous

connection), simplified surgical

technique with the sutureless

approach is associated with

favorable outcomes.

configuration is associated with a higher incidence of postrepair pulmonary vein stenosis, which can be ameliorated with the sutureless repair. Of course, further studies will need to be undertaken to confirm both the increased risk of postrepair pulmonary vein stenosis associated with the antler configuration and the ameliorative effect of the sutureless technique with this lesion. It is reasonable, however, to postulate that the antler configuration is simply a proxy for a high level of geometric complexity-and this where the sutureless approach carries an advantage relative to conventional repairs with direct atriovenous anastomosis. As the geometry of incised pulmonary veins deviates from a simple straight incision (as in patients with a large, horizontally oriented pulmonary venous confluence) to a more complex incision (eg, with the antler configuration), the sutureless approach becomes increasingly valuable through allowing creation of a geometrically simpler anastomosis (eg, an oval anastomosis to the posterior pericardium that encompasses the incised pulmonary veins). Shi and colleagues ${ }^{1}$ have added support to the general principle that simplification of technique, wherever possible, is often a wise approach.

\section{Reference}

1. Shi G, Zhu F, Wen C, Qiu L, Zhang H, Zhu Z, et al. Single-institutional outcomes of surgical repair of infracardiac total anomalous pulmonary venous connection. J Thorac Cardiovasc Surg. 2021;161:1408-17.e2. 